\title{
System Life and Reliability Modeling of a Multiple Power Takeoff Accessory Gearbox Transmission
}

\section{Kai Wang ( $\sim 2227068783 @ q q . c o m)$}

AECC Sichuan Gas Turbine Establishment https://orcid.org/0000-0001-8601-8364

\section{Xian-Liang Wang}

AECC Sichuan Gas Turbine Establishment

Jia-Zan Zhu

AECC Sichuan Gas Turbine Establishment

Dai-Song Ou

AECC Sichuan Gas Turbine Establishment

Dai-Feng Pan

AECC Sichuan Gas Turbine Establishment

Original Article

Keywords: Accessory gearbox, Power takeoff, Gear train, Life model, Reliability, Numerical program,

Posted Date: March 25th, 2020

DOI: https://doi.org/10.21203/rs.3.rs-19144/v1

License: (c) (1) This work is licensed under a Creative Commons Attribution 4.0 International License. Read Full License 
System Life and Reliability Modeling of a Multiple Power Takeoff Accessory Gearbox

Transmission

Kai Wang, Xian-Liang Wang, Jia-Zan Zhu, Dai-Song Ou and Dai-Feng Pan

AECC Sichuan Gas Turbine Establishment, Chengdu 610500, China

\begin{abstract}
:
A mathematical model for system life and reliability of a multiple power takeoff aeroengine accessory gearbox transmission was presented. The geometry model of accessory gear train system is distributed to multiple subsystems by the different transmitting powers. The subsystem is composed by three basic gear unit cases: spiral bevel gear unit, single mesh cylindrical gear unit and compound cylindrical gear unit. The lives of each component are combined to determine the unit life. The unit transmission and subsystem transmission interface models are defined to dispose the loads of common components in order to get the subsystem and the total system transmission life. A numerical example of a multiple power takeoff accessory gear train illustrates the use of this program. The initial design could not fulfill the design life requirement, and a design modification was performed to improve the system life and to balance the life of each component. The results of the redesign show that the accessory gear train has a more balanced life distribution by strengthening the weak parts of the transmission, and the overall life of total system is increased above the design requirement. This program can help the designer to approach an optimal accessory gearbox transmission design efficiently.
\end{abstract}

Key words: Accessory gearbox; Power takeoff ; Gear train; Life model; Reliability; Numerical program;

\title{
1 Introduction
}

Accessories like main fuel pump, lube pump, starter, hydraulic pump, integrated drive generator are mounted on an accessory gearbox (AGB) located on the fan case or on the core of an aircraft engine. The AGB provides electric, fuel, lube and hydraulic requirements, and plays a vital role in the operation of aeroengine and aircraft. General specification for aircraft turbojet and turbofan engines requires a special life and reliability limit for the accessory gear transmission. It's imperative for the designer that accessory gear train skeleton should be created to fulfill the specification's requirement in the preliminary design, which is an iterative process with manual intervention for moving designs across different design disciplines [1].

Mean time between overhauls (MTBO) or mean time between failures (MTBF) is an important property for the reliability of an AGB transmission module [2-5], since the engine maintenance cost is the major part of aircraft maintenance costs [6]. For a new transmission, a high MTBO means a long service life and a safe design. Selecting the extreme large MTBO or getting an over safety design leads to heavy, overdesigned gear transmission, and it is not conform to the aeroengine application. In the preliminary design, engine and aircraft requirements are not specified. The designer needs to change the gear trains and reevaluates a new design. The testing of gear transmission [7-9] is also used for evaluating its reliability in selecting an optimal gear trains, but it is time consuming and expensive for tests to obtain accurate results. In cases such as this, computer programs come to the aid of the designer. 
The Lundberg-Palmgren fatigue life model [10-12] is usually used for the life analysis of different types of bearings, and is also used for the analysis of fatigue lives of spur, helical [13-15] and bevel gears [16] assuming surface pitting as the eventual mode of failure. The reliability model is based on the reliabilities of the individual gears and bearings and is a two-parameter Weibull distribution in nature $[17,18]$. It's widely used in the numerical study of a single planet transmission or a combinational reduction transmission with single power input and single power output [19-23]. However, it's much more complex for a multiple power takeoff accessory gear transmission, since their components belong to multiple power flows and the loads of the common components combined in different angles, while those are not included in the previous models.

In this paper, system life and reliability modeling of a multiple power takeoff AGB transmission was developed. The system geometry model is distributed to subsystems by their power transmitted, and each subsystem contains typical units. These units include spiral bevel gear unit, single mesh cylindrical gear unit and compound cylindrical gear unit, which could compose most AGB gear train of an aeroengine. Examples are presented to illustrate the effect of the program. An initial design of AGB transmission shows a low system life, and an optimized one is performed to give a more reasonable design.

\section{Motion Analyses and Component Load}

\subsection{Transmission Configurations}

A typical AGB gear train of an aeroengine under consideration is shown in Figure 1. The input shaft of inlet gearbox (IGB) is the aeroengine's high pressure shaft. Power of aeroengine turbine flows to IGB, transfer gearbox (TGB) and AGB in series, and flows to the accessories mounted on the AGB finally. The couplings between each gearbox are assumed to be splines, only able to transmit torque loads between them. IGB and TGB have a Spiral bevel gear unit separately. Figure 1 shows three accessories A1, A2 and A3 on the AGB for this analysis. Accessories A1 and A2 are transmitted by single mesh cylindrical gear unit from their input gear shaft AGB SH2 and AGB SH1. Accessory A3 is transmitted by compound cylindrical gear unit from its input gear shaft AGB SH1. It may contain more accessories in other aeroengine applications, which could perform the gear train skeleton by adding additional gear units.

Figure 1 Typical AGB gear train

There are four power flows identified by different input and output powers for AGB gear train shown in Figure 1, which are named Subsystem 1, 2, 3 and 4. Gear train of Subsystem 1 (S1) includes IGB, TGB and the shaft AGB SH1. Subsystem 2 (S2) includes gear shafts AGB SH1 and AGB SH2. Similarity, shafts AGB SH1, AGB SH4 and AGB SH5 compose Subsystem 4 (S3), and shafts AGB SH2 and AGB SH3 compose Subsystem 3 (S4). Each subsystem is composed of the three basic gear units or their combination.

\subsection{Basic Gear Unit Cases}

Three basic gear unit cases comprise the transmission power flow subsystems. These unit cases are: spiral bevel gear unit, single mesh cylindrical gear unit and compound cylindrical gear unit, as shown schematically in Figure 2, Figure 3 and Figure 4. 
Figure 2 Spiral bevel gear unit

Figure 3 Single mesh cylindrical gear unit

Figure 4 Compound cylindrical gear unit

Each unit case has the input and output gears supported by two bearings: bearing 1 and bearing 2 from left to right. The locations of input and output gears are specified by distance $A$ and $B, A$ is measured from gear center to bearing 1 center, $B$ is measured from gear center to bearing 2 center. Compound cylindrical gear unit includes an intermediate shaft carried two intermediate gears supported on two bearings, which are named bearing 1, bearing 2 and gear 1, gear2 from left to right respectively. The distances $C, D$ and $E$ locate these gears. $C$ is measured from gear 1 center to bearing 1 center; $D$ is measured from gear 1 center to gear 2 center; $E$ is measured from gear 2 center to bearing 2 center. The shaft angle $\Sigma$ is the angle between the input gear axis and the output gear axis for spiral bevel gear unit. For compound cylindrical gear unit, the shaft angle $\Sigma$ is measured from the input shaft and intermediate shaft center-line to the intermediate shaft and output shaft center-line, counterclockwise about the intermediate shaft looked at from the input shaft, as shown in Figure 4.

Figure 5 Spiral bevel gear forces

For a spiral bevel gear unit, the gear forces include $F_{\mathrm{t}}, F_{\mathrm{r}}$ and $F_{\mathrm{a}}$, as shown in Figure 5. These forces are dependent on the direction of the spiral hand, the direction of rotation and whether it is a driver or a driven gear. The gear forces can be obtained

$$
\begin{gathered}
F_{\mathrm{t}}=\frac{2 T}{d_{\mathrm{m}}} \\
F_{\mathrm{r}}=\frac{F_{\mathrm{t}}}{\cos \beta_{\mathrm{m}}}\left(\tan \alpha_{\mathrm{n}} \cos \delta \pm \sin \beta_{\mathrm{m}} \sin \delta\right) \\
F_{\mathrm{a}}=\frac{F_{\mathrm{t}}}{\cos \beta_{\mathrm{m}}}\left(\tan \alpha_{\mathrm{n}} \sin \delta \mp \sin \beta_{\mathrm{m}} \cos \delta\right)
\end{gathered}
$$

Where $F_{\mathrm{t}}, F_{\mathrm{r}}$ and $F_{\mathrm{a}}$ are the tangential, radial and axial load; $T$ is the torque; $d_{\mathrm{m}}$ is the mean pitch diameter; $\beta_{\mathrm{m}}$ is the spiral angle; $\alpha_{\mathrm{n}}$ is the normal pressure angle at pitch surface; $\delta$ is the pitch angle.

Eqs. (1)-(3) are for a right-hand driving gear rotated clockwise or a left-hand driving gear rotated counterclockwise. These equations are also for a right-hand driven gear rotated counterclockwise or a left-hand driven gear rotated clockwise. For the other four cases the sign of the last term is switched. The direction of spiral hand is taken as seen from the apex looking towards back side of the gear. The direction of rotation is taken as seen from the back side of the 
gear looking towards the apex.

Eqs. (1)-(3) can also be applied to cylindrical gear unit with spur or helical gears. For the spur gear, $\beta_{\mathrm{m}}$ and $\delta$ are zero. For the helical gear, $\beta_{\mathrm{m}}$ is the helical angle and $\delta$ is zero.

The bearing supporting the gear have reactions in three directions: axial, radial and tangential, which act in the same plane of gear loads. The bearing axial reaction equal to the axial gear load if it is the only bearing can stand axial load, or equal to half of the axial gear load if two bearings share this load.

The tangential bearing reactions are:

$$
\begin{aligned}
& F_{\mathrm{bt} 1}=F_{\mathrm{t}} \frac{B}{A+B} \\
& F_{\mathrm{bt} 2}=F_{\mathrm{t}} \frac{A}{A+B}
\end{aligned}
$$

The radial bearing reactions are:

$$
\begin{aligned}
F_{\mathrm{br} 1}= & \frac{F_{\mathrm{r}} \cdot B+\frac{F_{\mathrm{a}} \cdot r \cdot A}{|A|}}{A+B} \\
F_{\mathrm{br} 2}= & \frac{F_{\mathrm{r}} \cdot A-\frac{F_{\mathrm{a}} \cdot r \cdot A}{|A|}}{A+B}
\end{aligned}
$$

Where $F_{\mathrm{bt} 1}$ and $F_{\mathrm{bt} 2}$ are the tangential reactions of bearing 1 and bearing $2 ; F_{\mathrm{br} 1}$ and $F_{\mathrm{br} 2}$ are the radial reactions of bearing 1 and bearing $2 ; r$ is the mean pitch radius.

The distance $A$ is taken as positive for a straddle mounting and negative for an overhung mounting. For the intermediate shaft or a shaft within more than one gear, the bearing reactions in each direction are the vector sums of the react component of each gear, and then sum to the total bearing reaction force. For example, the total reaction of bearing 1 is

$$
F_{\mathrm{b} 1}=\sqrt{F_{\mathrm{bt} 1}^{2}+F_{\mathrm{br} 1}^{2}}
$$

Where $F_{\mathrm{b} 1}$ is the total reaction of bearing 1 .

For the intermediate shaft with two gears, the analysis for the bearing loads is performed in the similary way, but the variables $C, D$ and $E$ are used to define the distances between gears and bearings instead of variables $A$ and $B$, as shown in Figure 4 .

\subsection{Contact Line Length}

The length of contact line is an important parameter for evaluating the gear tooth capacity. It is easy to get the value of contact line length by formular equations for spur and helical gears [24], as

$$
Z=\left(r_{\mathrm{O} 1}^{2}-r_{\mathrm{b} 1}^{2}\right)^{0.5} \pm\left[\left(r_{\mathrm{O} 2}^{2}-r_{\mathrm{b} 2}^{2}\right)^{0.5}-\left(r_{1}+r_{2}\right) \cdot \sin \alpha_{\mathrm{r}}\right]
$$

Where $Z$ is the length of contact line of cylindrical gear pair; $r_{\mathrm{O} 1}, r_{\mathrm{b} 1}, r_{1}$ and $r_{\mathrm{O} 2}, r_{\mathrm{b} 2}, r_{2}$ are the addendum radius, base and pitch radius of pinion and gear, respectively; $\alpha_{\mathrm{r}}$ is the operating transverse pressure angle. Double signs are used in Eq. (9), the upper sign applies to external gears and the lower sign applies to internal gears. 
It is more complicated for spiral bevel gear to get the value of contact line length. There are two ways to obtain spiral bevel gear's contact line length: by tooth contact analysis (TCA) and by formular equations. Here the AGMA design standard [25], the length of contact line is given by:

$$
s=\frac{b \cdot Z_{\mathrm{N}} \cdot \eta_{\mathrm{I}} \cdot \cos \beta_{\mathrm{b}}}{\eta^{2}}
$$

Where $s$ is contact line length of spiral bevel gear pair; $b$ is net face width; $Z_{\mathrm{N}}$ is length of action in mean normal section; $\eta$ and $\eta_{\mathrm{I}}$ are intermediate variables; $\beta_{\mathrm{b}}$ is mean base spiral angle.

\subsection{Unit Transmission and Subsystem Transmission Interface}

In a multiple power takeoff AGB gear transmission, it contains several accessory power takeoff shafts and may have two or more power branches from the main power train in the interface shaft. The total transmission system is composed of subsystems which have a certain translation power, and the sum of each subsystem's takeoff power is the total system input power. Subsystem is composed of the basic gear units as described in the previous section.

The output shaft of the first unit should be the same as the input shaft of the second unit, or they are two shafts in the same center line connected by splines solidly into a whole one, which is defined as the interface shaft. In a subsystem, the structure of interface shaft between units can be sorted in three types, as shown in Figure 6. The hollow arrow is the power output of the first unit, and the solid arrow is the power input of the next unit. In Figure 6(a), they act on the same gear. In Figure 6(b), they are act on two different gears. Both Figure 6(a) and Figure 6(b) contain a single shaft with two bearings. In Figure 6(c), they act on two gears in two shafts with their own bearings supporting.

Figure 6 unit interface

The power flows in the main power train as the first subsystem. One or more new subsystems should be created when a power branch joint or a power takeoff joint appear. The power branch joint is the interface shaft where two or more power outputs are driven in different directions. The power takeoff joint is the interface shaft where one or two accessories are mounted at each end pad to deliver power. These joints are named subflow joint and subpower joint separately, and form the subsystem interface. The subpower joint is the same to Figure 6(a) and Figure 6(b). The subflow joint is shown in Figure 7. Similarity, the hollow arrow is the power output of the first subsystem, and the solid arrow is the power input of the next subsystems. In a subflow joint, there may be two or three flow branches, and here the maximum number of branches is set to three. These cases in Figure 7 can construct most accessory gear trains of current aeroengines.

Figure 7 Subflow joint

The interface shaft is the common component for the connected subsystems or units. The bearings and gears on the common shaft are identical for the concerning subsystems or units. In a certain unit, the gears and bearings have steady loads, and they are analyzed as the components of a basic unit transmission. When the basic units assemble a subsystem or subsystems assemble the total system, the loads of gears and bearings should be vector superimposed for analyzing the life 
and reliability of subsystem transmission or total system transmission. An angle $\theta$ must be introduced to show the relationship of each force vector or power flow direction vector, as shown in Figure 8. $\theta$ is measured counter clockwise from the output of the first unit gear load to the input of the second or third unit gear load seen from bearing 1 looking towards bearing 2 . Gear forces could be combined by angle, $\theta$, and then it is used for bearing forces combination. The superimposed bearing forces on each bearing are given by Eq. (11)-(13).

Figure 8 Gear force superposition

$$
\begin{gathered}
F_{\mathrm{ba}}=F_{\mathrm{baI}}+F_{\mathrm{baII}}+F_{\mathrm{baII}} \\
F_{\mathrm{bt}}=F_{\mathrm{btI}}-F_{\mathrm{btII}} \cdot \cos \theta_{1}-F_{\mathrm{btII}} \cdot \cos \theta_{2} \\
F_{\mathrm{br}}=F_{\mathrm{brI}}+F_{\mathrm{brII}} \cdot \cos \theta_{1}+F_{\mathrm{brII}} \cdot \cos \theta_{2}
\end{gathered}
$$

Where $F_{\mathrm{ba}}, F_{\mathrm{bt}}$ and $F_{\mathrm{br}}$ are the axial, tangential and radial force of bearing, respectively; $F_{\mathrm{t}}$ and $F_{\mathrm{r}}$ are the tangential and radial force of gear as shown in Figure 8; $\theta_{1}$ and $\theta_{2}$ are the first and second output power flow direction angle relative to the input power in the interface shaft. Both in Figure 8 and Eq. (11)-(13), the subscript letters I, II and III indicate the first, second and third unit or subsystem, respectively.

\section{Lives and Dynamic Capacities}

\subsection{Bearing Life and Capacity}

The Lundberg-Palmgren model was used to predict bearing life for a long time. A modified equation with adjustment factors was developed for the technology improvement in the area of material, processing, manufacturing and operating conditions. The modified equation [26] is

$$
L_{10 \mathrm{~B}}=a_{\mathrm{B}}\left(\frac{C_{B}}{P_{B}}\right)^{p_{\mathrm{B}}}
$$

Where $L_{10 \mathrm{~B}}$ is the adjusted $90 \%$ reliability life of bearing in millions of load cycles; $a_{\mathrm{B}}$ is the life adjustment factor dependent on the bearing material and its processing; $C_{\mathrm{B}}$ is the basic dynamic load capacity; $P_{\mathrm{B}}$ is the equivalent load; The power, $p_{\mathrm{B}}$, is the load-life exponent, and the proposed value is 3 for ball bearings, 10/3 for roller bearings.

\subsection{Gear Life and Capacity}

Based on the Lundberg-Palmgren theory, the spur gear life [14] can be written as

$$
L_{10 \mathrm{G}}=\left(\frac{1}{z}\right)^{\frac{1}{e_{\mathrm{G}}}} \frac{L_{10 \mathrm{t}}}{k}
$$

Where $L_{10 \mathrm{G}}$ and $L_{10 \mathrm{t}}$ are the $90 \%$ reliability life of gear and a single gear tooth in millions of load cycles; $z$ is the number of teeth on the gear; $e_{\mathrm{G}}$ is the Weibull slope for the gear and is assumed to be $2.5 ; k$ is the ratio from tooth load cycles to the system input shaft, which makes all components 
on the same counting base.

For helical and spiral bevel gears, the gear lives are modeled as equivalent spur gears in the normal plane [23].

The $90 \%$ reliability life of a single gear tooth in millions of load cycles is

$$
L_{10 \mathrm{t}}=a_{\mathrm{t}}\left(\frac{C_{\mathrm{t}}}{P_{\mathrm{t}}}\right)^{p_{\mathrm{G}}}
$$

Where $a_{\mathrm{t}}$ is the life adjustment factor similar to that for rolling bearings; $C_{\mathrm{t}}$ is the basic load capacity of the gear tooth; $p_{\mathrm{G}}$ is the load-life exponent usually taken as $4.3 ; P_{\mathrm{t}}$ is the normal tooth load. For the intermediate gear in the interface shaft with multiple gear forces, $P_{\mathrm{t}}$ is the equivalent normal tooth load determined as follows:

$$
P_{\mathrm{t}}=\left(\frac{P_{\mathrm{t} 1}^{p_{\mathrm{G}}}+P_{\mathrm{t} 2}^{p_{\mathrm{G}}}+\ldots+P_{\mathrm{tn}}^{p_{\mathrm{G}}}}{n}\right)^{\frac{1}{p_{\mathrm{G}}}}
$$

Where $P_{\mathrm{t} 1}, P_{\mathrm{t} 2}, \ldots, P_{\mathrm{tn}}$ are the normal tooth load of gear mesh $1,2, \ldots, \mathrm{n}$.

The basic load capacity of the gear tooth is

$$
C_{\mathrm{t}}=B_{m} \cdot b^{0.907} \rho^{-1.165} l^{-0.093}
$$

Where

$$
\rho=\left(\frac{1}{\rho_{1}}+\frac{1}{\rho_{2}}\right) \frac{1}{\sin \alpha_{\mathrm{n}}}
$$

Where $B_{\mathrm{m}}$ is a material constant; $l$ is length of stressed track, for spur and helical gears, its value equals to $Z$ in Eq. (9), and for spiral bevel gear, its value equals to $s$ in Eq. (10); $b$ is the net face width for spur gear, and is the effect face width for helical and spiral bevel gears. $\rho$ is the curvature sum at the start of single tooth contact; $\rho_{1}$ and $\rho_{2}$ are the radii of curvature of the pinion tooth surface and gear tooth surface at the contact point.

\subsection{System Life and Capacity}

The reliabilities of the individual bearing and gear are assumed to be a strict series. The lives of each component are combined to determine the system life using the two-parameter Weibull distribution function [13], as follows:

$$
\ln \left(\frac{1}{R_{\mathrm{S}}}\right)=\ln \left(\frac{1}{0.9}\right) \cdot \sum_{i=1}^{n}\left(\frac{L_{\mathrm{S}}}{L_{10, i}}\right)^{e_{i}}
$$

Where $R_{\mathrm{S}}$ and $L_{\mathrm{S}}$ are the reliability and the life of the entire system; $e_{i}$ and $L_{10, i}$ are the Weibull slope and the $90 \%$ reliability life of component $i ; n$ is the number of components.

Components such as gear and different types of bearings have different Weibul slopes. Eq. (20) can be solved at a reliability range, and the values of reliability versus life are plotted on Weibull paper. Using a least-squares fit, the Weibul slope of entire system can be determined, and then the two-parameter Weibull distribution with the system reliability can be written as:

$$
\ln \left(\frac{1}{R_{\mathrm{S}}}\right)=\ln \left(\frac{1}{0.9}\right) \cdot\left(\frac{L_{\mathrm{S}}}{L_{10, \mathrm{~S}}}\right)^{e_{\mathrm{S}}}
$$


Where $e_{\mathrm{S}}$ and $L_{10, \mathrm{~S}}$ are the Weibull slope and the $90 \%$ reliability life of the entire system.

The system mean life is the average of the mean lives of the individual components. The failure rate is defined as the reciprocal of the mean life, and the transmission system life is given as:

$$
\frac{1}{L_{\mathrm{av}, \mathrm{S}}}=\sum_{i=1}^{n} \frac{1}{L_{\mathrm{av}, i}}
$$

Where $L_{\mathrm{av}, \mathrm{S}}$ and $L_{\mathrm{av}, \mathrm{i}}$ are the mean life of entire system and component $i$.

Using the Palmgren load-life model in terms of component torques and lives, Eq. (20) becomes:

$$
1=\sum_{i=1}^{n}\left(\frac{C_{\mathrm{S}}}{C_{i}}\right)^{e_{i} \cdot p_{i}}
$$

Where $C_{\mathrm{S}}$ and $C_{\mathrm{i}}$ are the basic dynamic capacity of entire system and component $i$; $p_{\mathrm{i}}$ is the load-life exponent of component $i$.

Different reliability lives of system are calculated at various input torques. The negative reciprocal of load-life exponent of entire system can be found using a linear regression which is similar to the calculation of Weibul slope. The basic dynamic capacity of system is given by:

$$
L_{10, \mathrm{~S}}=\left(\frac{C_{\mathrm{S}}}{T_{\mathrm{I}}}\right)^{p_{\mathrm{S}}}
$$

Where $p_{\mathrm{S}}$ is the load-life exponent of entire system; $T_{\mathrm{I}}$ is the input torque of the transmission system.

\section{Program Structure}

The flow chart of the program is shown in Figure 9. AGB gear train as a whole transmission system contains a series of connected subsystems and each subsystem contains one or more units. All units should be one of the three basic unit cases, which are the basic input modules in the input file. The input file contains various parameters, which include the input power, speed and direction of input shaft rotation, units, subsystems and total system configuration, properties and configurations of all gears and bearings, and also the interface shaft geometry and properties. The output gear train layout, subsystem knot diagram and orthographic projection can be used for checking the transmission configuration, where $\mathrm{S} 1, \mathrm{~S} 2, \ldots, \mathrm{Sn}$ are the subsystem 1, subsystem 2, ..., subsystem $\mathrm{n}$. The life and capacity of each component in unit transmission are determined, and then the life and capacity of unit can be obtained. When the calculation of all units in a subsystem is done, the life and capacity results of the subsystem can be obtained. The results of each subsystem can be used to get the life and capacity results of the entire system.

Figure 9 Program flow chart

\section{Applications}

\subsection{Numerical Example}

A multiple power takeoff accessory gearbox transmission used for this analysis consists of IGB, TGB and AGB, as shown in Figure 1. The IGB and TGB consist of a spiral bevel gear mesh 
separately. The AGB consist of three accessories: A1, A2 and A3. The input power is $150 \mathrm{~kW}$ at the speed of $15000 \mathrm{r} / \mathrm{min}$ in the counter clockwise looked towards the flying direction. Gears are initially designed to satisfy the requirement of bending strength and pitting resistance. Bearings are usually selected from the bearing catalogue or from the past experience in similar applications. The basic gear and bearing parameters are listed in Table 1 and Table 2.

Table 1 Basic gear parameters

\begin{tabular}{lllllll}
\hline Gear description & $\begin{array}{l}\text { Number } \\
\text { of teeth }\end{array}$ & $\begin{array}{l}\text { Module } \\
(\mathrm{mm})\end{array}$ & $\begin{array}{l}\text { Pressure } \\
\text { angle }\left({ }^{\circ}\right)\end{array}$ & $\begin{array}{l}\text { Face width } \\
(\mathrm{mm})\end{array}$ & $\begin{array}{l}\text { Spiral } \\
\text { angle }\left(^{\circ}\right)\end{array}$ & $\begin{array}{l}\text { Hand } \\
\text { spiral }\end{array}$ \\
\hline IGB input gear & 37 & 4.2 & 20 & 25 & 35 & Left \\
IGB output gear & 35 & 4.2 & 20 & 25 & 35 & Right \\
TGB input gear & 29 & 4.2 & 20 & 25 & 35 & Right \\
TGB output gear & 31 & 4.2 & 20 & 25 & 35 & Left \\
AGB SH1 gear & 37 & 2 & 25 & 12 & 0 & -- \\
AGB SH2 gear & 67 & 2 & 25 & 12 & 0 & -- \\
AGB SH3 gear & 63 & 2 & 25 & 6 & 0 & -- \\
AGB SH4 gear1 & 63 & 2 & 25 & 6 & 0 & -- \\
AGB SH4 gear2 & 37 & 2 & 25 & 8 & 0 & -- \\
AGB SH5 gear & 73 & 2 & 25 & 8 & 0 & -- \\
\hline
\end{tabular}

Table 2 Basic bearing parameters

\begin{tabular}{llllll}
\hline Bearing description & $\begin{array}{l}\text { Bore } \\
\text { diameter } \\
(\mathrm{mm})\end{array}$ & $\begin{array}{l}\text { Outside } \\
\text { diameter } \\
(\mathrm{mm})\end{array}$ & $\begin{array}{l}\text { Width } \\
(\mathrm{mm})\end{array}$ & $\begin{array}{l}\text { Basic } \\
\text { dynamic } \\
\text { capacity } \\
(\mathrm{kN})\end{array}$ & $\begin{array}{l}\text { Static } \\
\text { capacity of } \\
\text { ball bearing } \\
(\mathrm{kN})\end{array}$ \\
\hline $\begin{array}{l}\text { IGB input bearing1 } \\
\text { IGB input bearing2 }\end{array}$ & 100 & 180 & 30 & 130 & 135 \\
$\begin{array}{l}\text { IGB output bearing1, } \\
\text { TGB input bearing1, }\end{array}$ & 40 & 150 & 24 & 145 & -- \\
$\begin{array}{l}\text { TGB output bearing1 } \\
\text { IGB output bearing2, }\end{array}$ & & 70 & 20 & 45 & -- \\
$\begin{array}{l}\text { TGB input bearing2, } \\
\text { TGB output bearing2 } \\
\text { All bearings in AGB } \\
\text { except AGB SH5 }\end{array}$ & 40 & 68 & 15 & 30 & 20 \\
bearing2 & & 62 & 16 & 20.3 & 11.2 \\
AGB SH5 bearing2 & 25 & 52 & 15 & 14.8 & 7.8 \\
\hline
\end{tabular}

\subsection{Discussion of Results}

The GUI interface of the program is shown in Figure 10. The decomposed gear train skeleton, subsystem knot diagram and orthographic projection are shown in the upside of Figure 10. They are utilized to check whether the analyzing gear train is consistent with the required layout and the input parameters in the input file is correct. There are four subsystems in this gear train. For the initial design 1 as shown in Table 1 and Table 2, the lives of total system and each subsystem 
presented in the Weibull plot are shown in Figure 11. It can be found that the subsystem 1 has the largest life against the other three subsystems. The life data of subsystem 2 is the most close to the total system, and it is the weakest part of the entire transmission. By further examination, it can be seen from Figure 12, which shows the mean life and dynamic capacity of entire system and each component. These results show that the gears in AGB have the lowest life under the design requirement of 10000 hours except AGB SH4 gear 2. AGB SH1 gear has a special low life of 892 hours, which dominates the life and dynamic capacity of the total transmission. For total system, the life is only 898 hours, and the value of dynamic capacity is $250 \mathrm{~N} \cdot \mathrm{m}$ by converting into input torque. It can also be found that the lives of each component in this gear train are not balanceable, where the values of the bearings are much higher than gears'. In order to improve this transmission, some change of gears and bearings are done in design 2 as listed in Table 3 and Table 4, and they only show the values of components which are changed compared with design 1.

Figure 10 GUI interface of the program

Figure 11 Life versus probability of system failure (Design 1)

Figure 12 Life and dynamic capacity of total system and each component (Design 1)

Table 3 Basic parameters of the redesigned gears

\begin{tabular}{llllllll}
\hline Gear description & $\begin{array}{l}\text { Number } \\
\text { of teeth }\end{array}$ & $\begin{array}{l}\text { Module } \\
(\mathrm{mm})\end{array}$ & $\begin{array}{l}\text { Pressure } \\
\text { angle }\left(^{\circ}\right)\end{array}$ & $\begin{array}{l}\text { Face width } \\
(\mathrm{mm})\end{array}$ & $\begin{array}{l}\text { Spiral } \\
\text { angle }\left(^{\circ}\right)\end{array}$ & $\begin{array}{l}\text { Hand } \\
\text { spiral }\end{array}$ & of \\
\hline AGB SH1 gear & 33 & 2.5 & 25 & 18 & 0 & -- \\
AGB SH2 gear & 59 & 2.5 & 25 & 18 & 0 & -- \\
AGB SH3 gear & 55 & 2.5 & 25 & 10 & 0 & -- \\
AGB SH4 gear1 & 56 & 2.5 & 25 & 12 & 0 & -- \\
AGB SH4 gear2 & 33 & 2.5 & 25 & 12 & 0 & -- \\
AGB SH5 gear & 65 & 2.5 & 25 & 12 & 0 & -- \\
\hline
\end{tabular}

Table 4 Basic parameters of the redesigned bearings

\begin{tabular}{llllll}
\hline Bearing description & $\begin{array}{l}\text { Bore } \\
\text { diameter } \\
(\mathrm{mm})\end{array}$ & $\begin{array}{l}\text { Outside } \\
\text { diameter } \\
(\mathrm{mm})\end{array}$ & $\begin{array}{l}\text { Width } \\
(\mathrm{mm})\end{array}$ & $\begin{array}{l}\text { Basic } \\
\text { dynamic } \\
\text { capacity } \\
(\mathrm{kN})\end{array}$ & $\begin{array}{l}\text { Static } \\
\text { capacity of } \\
\text { ball bearing } \\
(\mathrm{kN})\end{array}$ \\
\hline $\begin{array}{l}\text { All bearings in AGB } \\
\text { except AGB SH5 }\end{array}$ & 30 & 55 & 13 & 13.8 & 8.3 \\
$\begin{array}{l}\text { bearing2 } \\
\text { AGB SH5 bearing2 }\end{array}$ & 25 & 47 & 8 & 8.06 & 4.75 \\
\hline
\end{tabular}

For the design 2, the system Weibull plots are shown in Figure 13, and the life and dynamic 
capacity values of components and the total system are shown in Figure 14. The life of subsystem 4, subsystem 3 and subsystem 2 increased significantly, since the AGB gears modified by changing module, face width and number of teeth, but the gear ratio of each accessory changed only slightly. The lives of the AGB gears are increased by increasing their dynamic capacities. The lives and dynamic capacities of AGB bearings in design 2 are declined compared to the results of design 1, since these bearings are reselected with smaller size and lower basic dynamic capacities, but they are still much higher than the values of gears'. For total system transmission, the dynamic capacity equals to $467 \mathrm{~N} \cdot \mathrm{m}$, and the life is 10093 hours which is above the design requirement. This indicates that the weakest part of the gear train is the AGB gears. When those components are strengthened, the entire system will get a much higher MTBO. However, the design 2 of this AGB gear train may not be the best solution and can also be improved by a further optimization.

Figure 13 Life versus probability of system failure (Design2)

Figure 14 Life and dynamic capacity of total system and each component (Design2)

\section{Conclusions}

A system life and reliability model of a multiple power takeoff accessory gearbox was developed by the combination of the models of individual bearings and gears. The system geometry model is distributed to subsystems by the different transmitting powers, and each subsystem is composed by the three basic gear unit cases: spiral bevel gear unit, single mesh cylindrical gear unit and compound cylindrical gear unit. The lives of each component are combined to determine the unit life. By using the unit transmission and subsystem transmission interface models, the loads of common components are recalculated to get the subsystem and the total system transmission life sequentially. A numerical example of a multiple power takeoff AGB gear train is presented to illustrate the use of the program. The results of the initial design 1 show the AGB gears are the critical parts of the gear train, and the total system life is 898 hours which is not satisfy the requirement of design. Design 2 as a modification was performed to improve the system life and to balance the life of each component. The results of this redesign show that the AGB gear train has a more balanced life distribution, and the overall life of total system is increased to 10093 hours above the design requirement. When the weak components are strengthened, the entire system will get a much higher MTBO. However, the design 2 of this AGB gear train may not be the best solution and can also be improved by a further optimization. This program can help the designer to approach an optimal AGB transmission design efficiently. 


\section{Declarations}

- Availability of data and materials

The datasets used and/or analyzed during the current study are available from the corresponding author on reasonable request.

- Competing interests

The authors declare that they have no competing interests.

- Funding

Not applicable.

- Authors' contributions

$\mathrm{K} \mathrm{W}$ wrote the manuscript and the major Matlab program codes. X-L W, J-Z Z, D-S O checked the program and amended the earlier proposal. D-F P assisted with the sample analysis. All authors read and approved the final manuscript.

- Acknowledgements

Not applicable.

- Authors' information (optional)

Kai WANG, born in 1985, is currently a senior engineer at AECC Sichuan Gas Turbine Establishment, Chengdu, China. He got a master degree on mechanical engineering in Shanghai Jiao Tong University in 2009. His research interest is mechanical transmission system of aeroengine. Tel: +83-028-83017691; E-mail: wangkaixjd@163.com. 


\section{References}

1. CHAUDHARI V, MONIZ T, TARI C N, et al. Integrated preliminary design approach for turbomachinery design[R]. Proceedings of ASME Turbo Expo, 2011, 45546.

2. XU Kejun. Life control and management for military aero engine based on modular unit[J]. Journal of Naval Aeronautical Engineering Institute, 2007, 22(5): 541-547. (in Chinese)

3. DONG Yuge, ZHU Wenyu, CHEN Xinzhao. The fuzzy forecast of mechanical system reliability[J]. Mechanical Science and Technology, 1997, 16(4): 585-589. (in Chinese)

4. WANG Tongbei, CHEN Meiying. Some issues on aeroengine operational reliability[J]. Aeroengine, 2005, 31(1): 1-5. (in Chinese)

5. INGISTOV S. Failures of the high energy, high pitch velocity gear boxes[R]. Proceedings of ASME Turbo Expo, 2004, 53262.

6. ZHAO Hongli, CHEN Duowen, GAO Jingdong. Optimization of aeroengine shop visit cost in its service life cycle[J]. International Journal of Plant Engineering and Management, 2018, 23(2): 79-88.

7. DEMPSEY P J, LEWICKI D G, DECKER H J. Investigation of gear and bearing fatigue damage using debris particle distributions[R]. NASA, 2004, 212883.

8. ZENG Yutian, LI Jinku. Test verification of accelerated fatigue life about wind power gearbox[J]. Mechanical Engineer, 2018, 9(2): 152-154. (in Chinese)

9. LIU Songyu, SHEN Yabin. Research on the wear reliability test technique of the transmission system assembly influential factors of helicopter based on orthogonal test design[J]. Helicopter Technique, 2017, (2): 56-60. (in Chinese)

10. ZARETSKY E V. Fatigue criterion to system design, life, and reliability[J]. Journal of Propulsion and Power, 1987, 3(1): 76-83.

11. ZARETSKY E V. Rolling bearing life prediction, theory, and application[R]. NASA, 2013, 215305.

12. LU Chunyu, LIU Shaojun. A fatigue life prediction method of rolling bearing under elliptical contact elastohydrodynamic lubrication[J]. Journal of Southeast University, 2017, 33(1): 46-52.

13. SAVAGE M, RADIL K C, LEWICKI D G, et al. Computerized life and reliability modelling for turboprop transmissions[R]. NASA, 1988, 100918.

14. ZARETSKY E V. Design of oil-lubricated machine components for life and reliability[R]. NASA, 2007, 214362.

15. WU Shangsheng, DUAN Fuhai, HU Qing Chun. The influence of allocation of systematic parameters on the reliability of multi-staged planet gear transmission[J]. Journal of Machine Design, 2007, 24(10): 43-46. (in Chinese)

16. SAVAGE M, PRASANNA M G, COE H H. Maximum life spiral bevel reduction design[R]. NASA, 1992, 105790,

17. HE Xiaocong. A study on weibull distribution for application of reliability model for double-reduction spur gear unit[J]. Journal of Kunming Institute of Technology, 1995, 20(5): 38-43. (in Chinese)

18. XUE Xiangzhen, LI Yuxi, WANG Sanmin. Method of lifetime and reliability of some helicopter's main reducer[J]. Journal of Aerospace Power, 2011, 26(3): 635-641. (in Chinese)

19. LI Ming, XIE Liyang, LI Haiyang, et al. Life distribution transformation model of planetary gear system[J]. Chinese Journal of Mechanical Engineering, 2018, 31(24): 1-8. 
20. LEWICKI D G, BLACK J D, SAVAGE M, et al. Fatigue life analysis of a turboprop reduction gearbox[R]. NASA, 1985, 87014.

21.Savage M, RUBADEUX K L, COE H E. Spur, helical, and spiral bevel transmission life modeling[J]. Journal of Propulsion and Power, 1996, 12(2): 283-288.

22. HU Qingchun, DUAN Fuhai, WU Shangsheng. Research on reliability of closed planetary transmission systems[J]. China mechanical Engineering, 2007, 18(2): 146-149. (in Chinese)

23. SAVAGE M, PRASANNA M G, RUBADEUX K L. TLIFE-a program for Spur, helical and spiral bevel transmission life and reliability modeling[R]. NASA, 1994, 4622

24. ANSI/AGMA 908-B89. Geometry factors for determining the pitting resistance and bending strength of spur, helical and herringbone gear teeth[S].

25. ANSI/AGMA 2003-B97, Rating the pitting resistance and bending strength of generated straight bevel, zerol bevel and spiral bevel gear teeth[S].

26. ZARETSKY E V. Rolling bearing steels - a technical and historical perspective[J]. Materials Science and Technology, 2012,28(1): 58-69. 


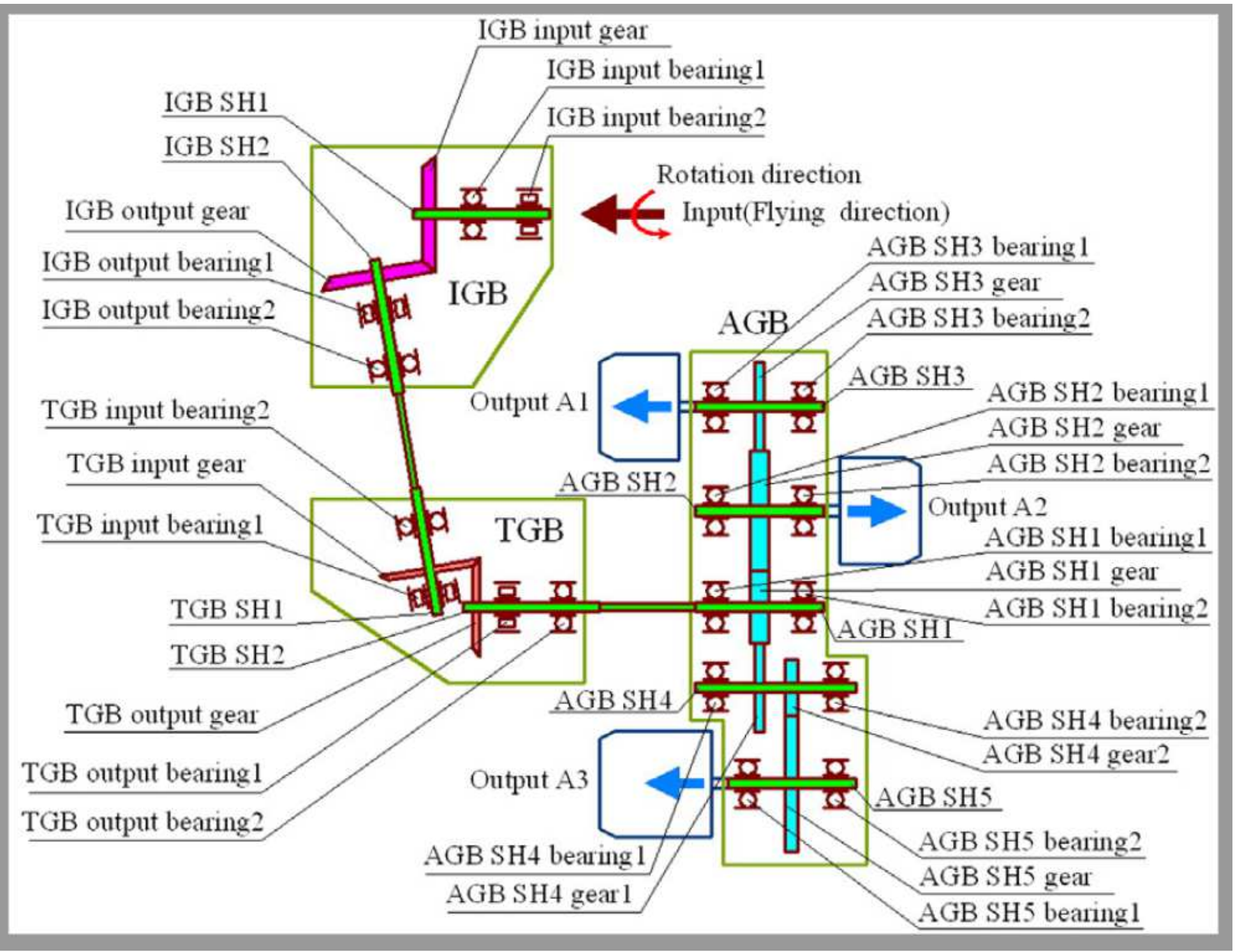

Figure 1

Typical AGB gear train 


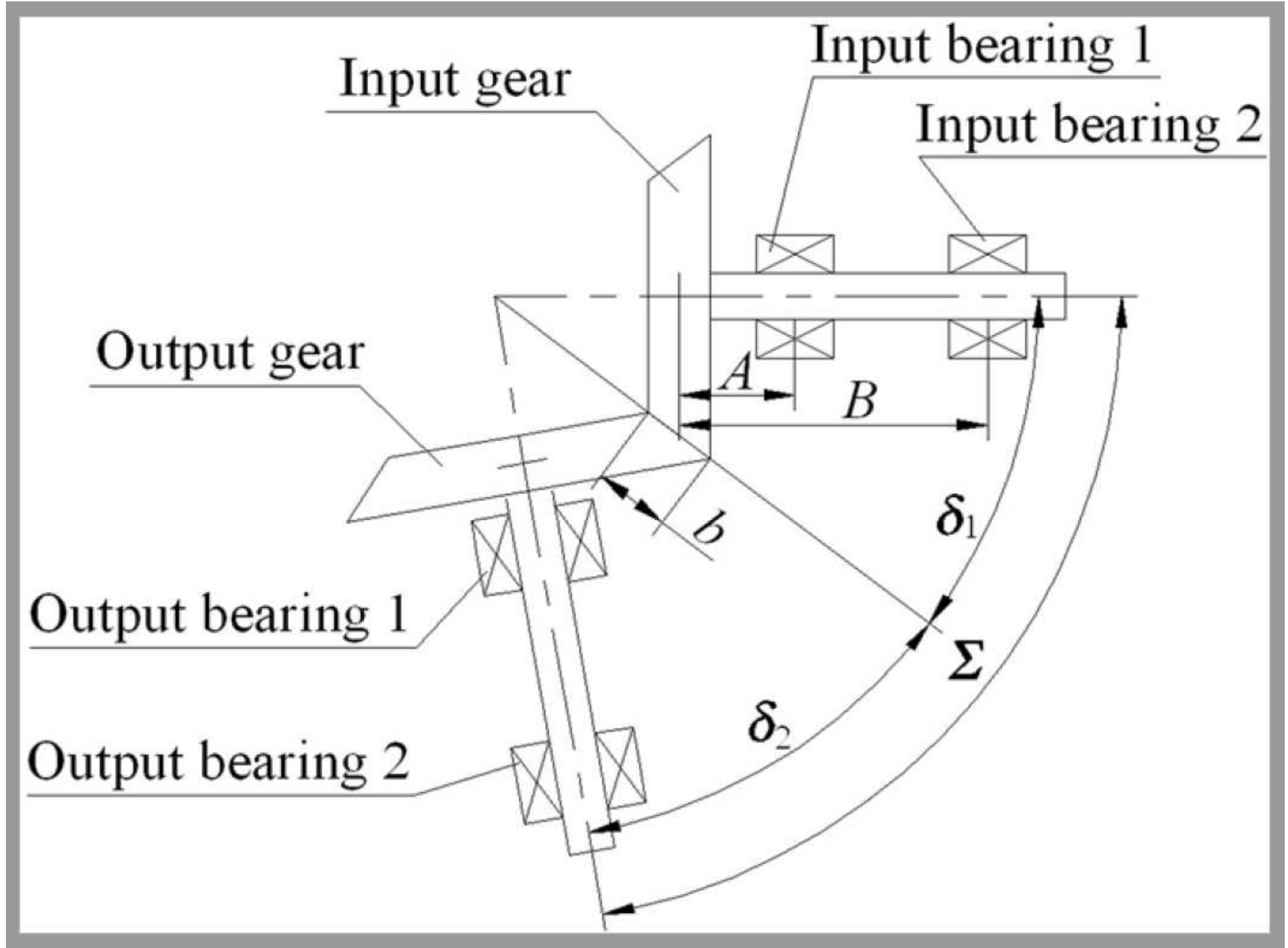

Figure 2

Spiral bevel gear unit 


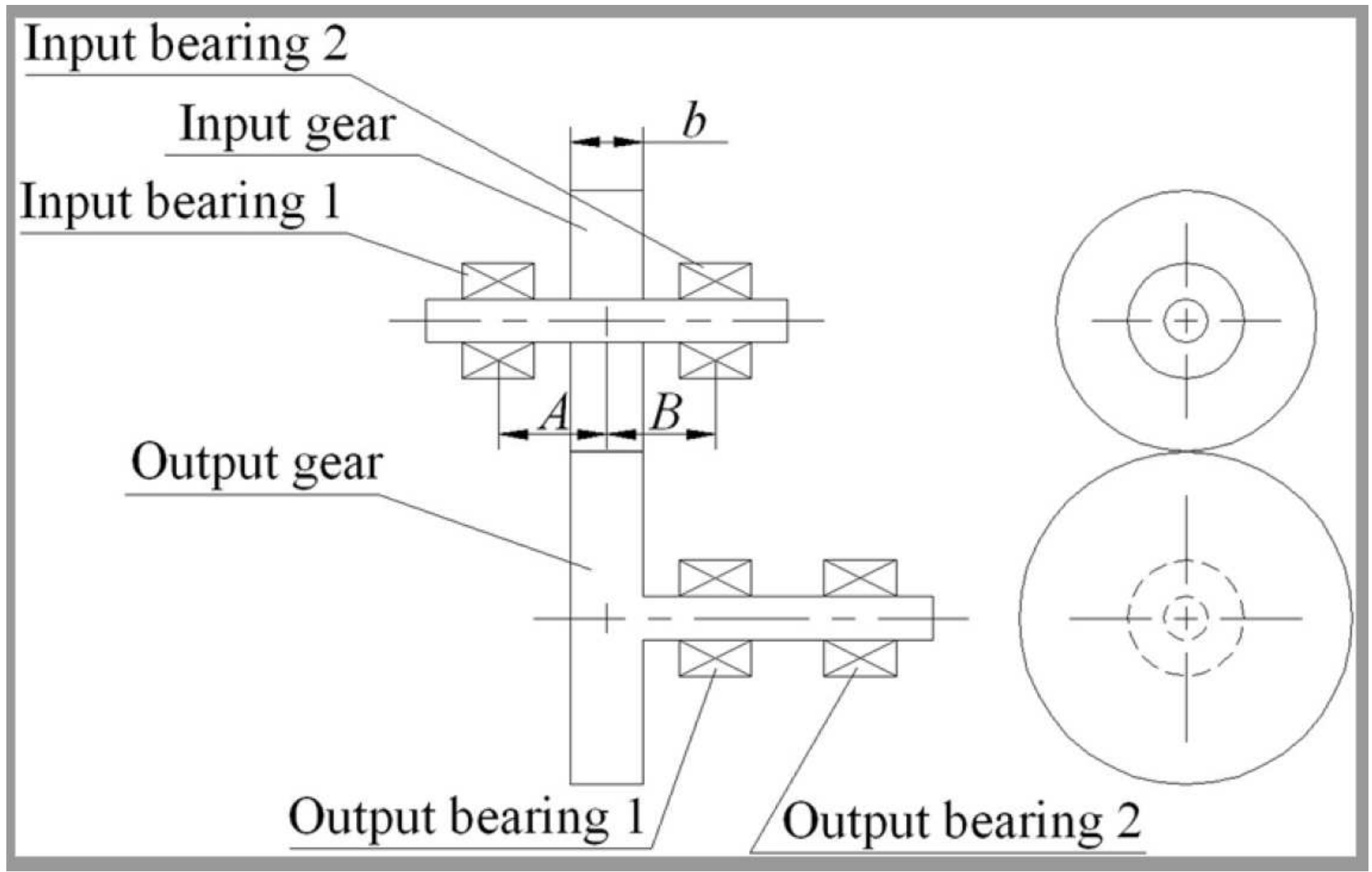

Figure 3

Single mesh cylindrical gear unit 


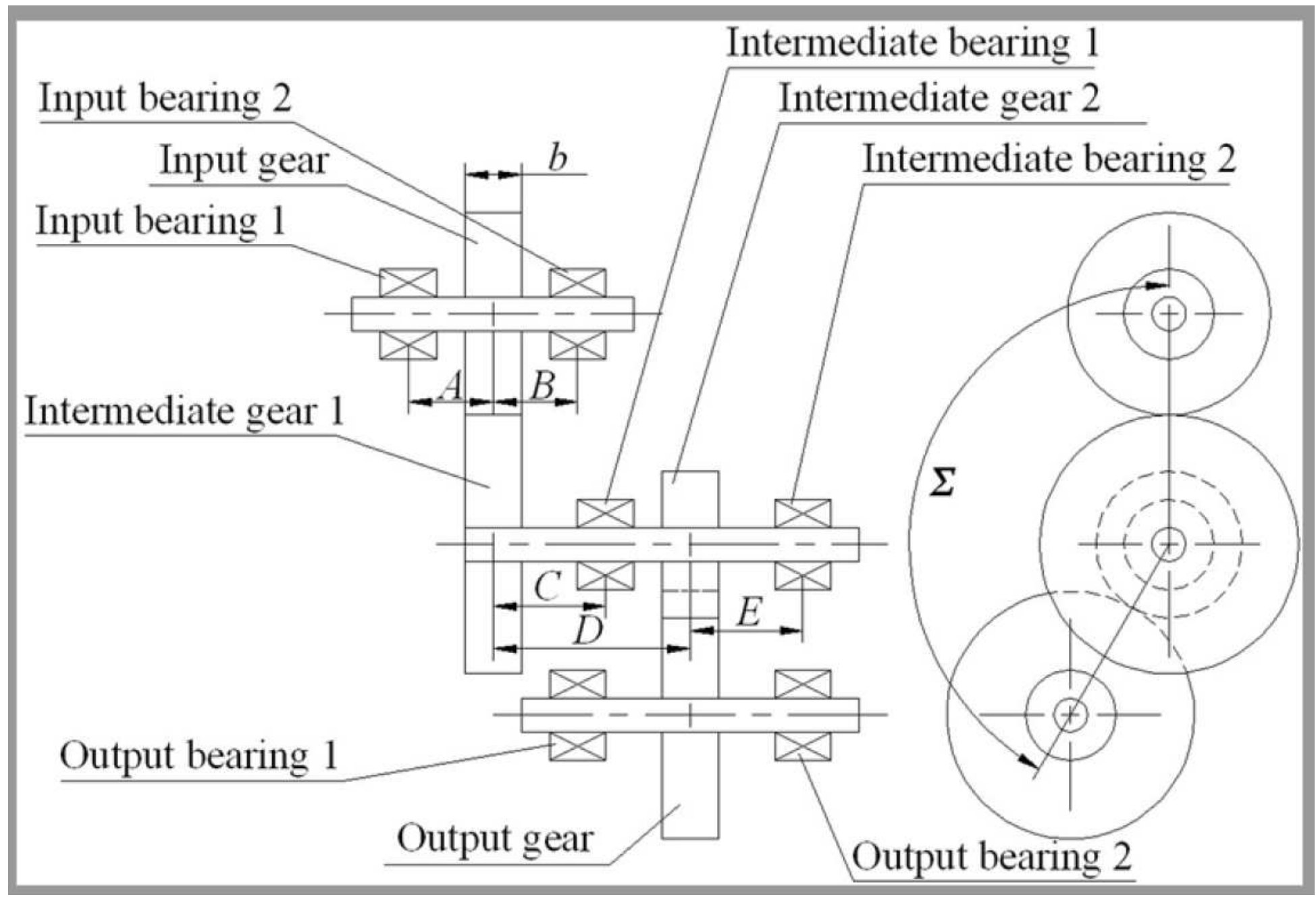

Figure 4

Compound cylindrical gear unit 


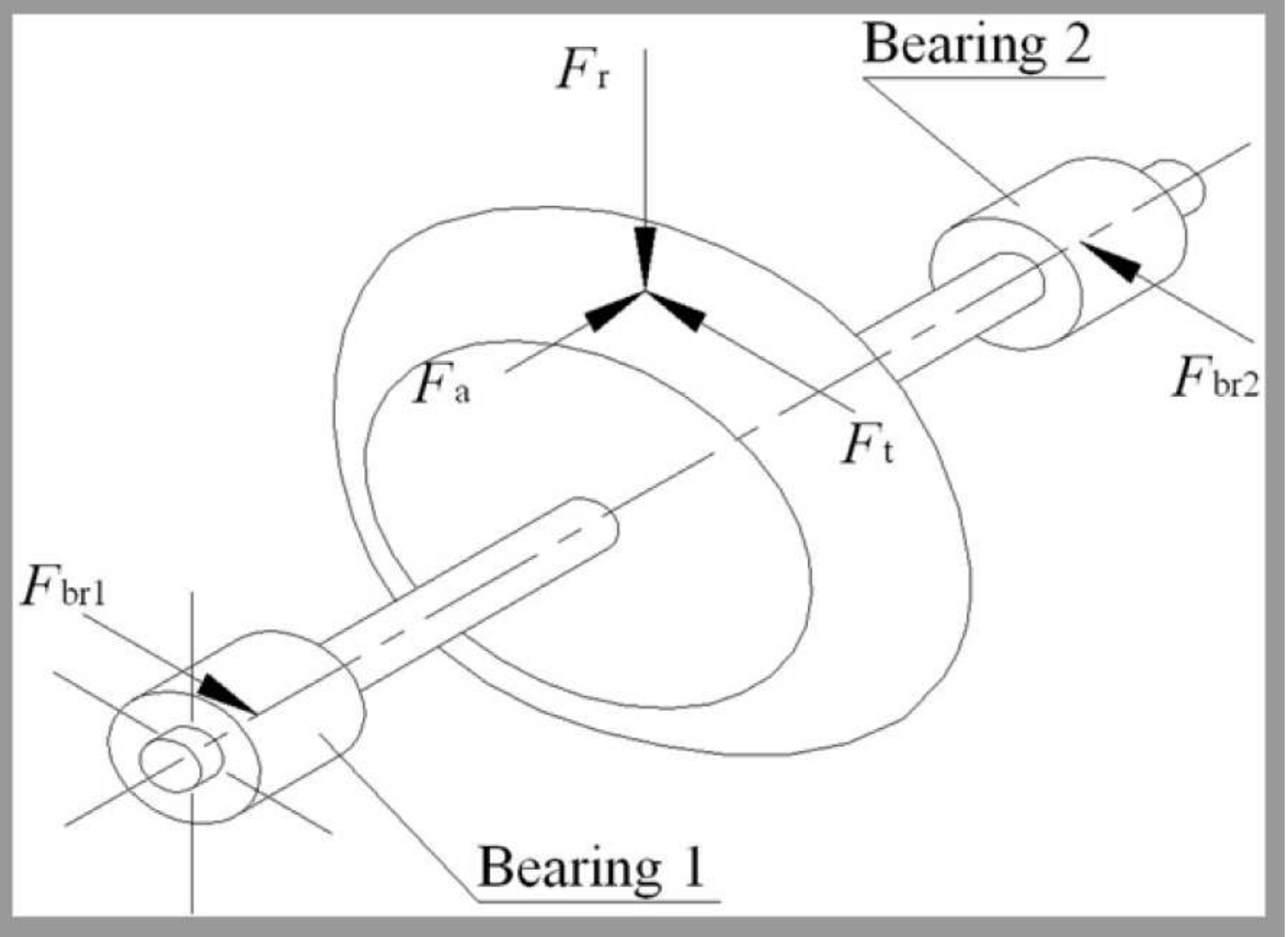

Figure 5

Spiral bevel gear forces

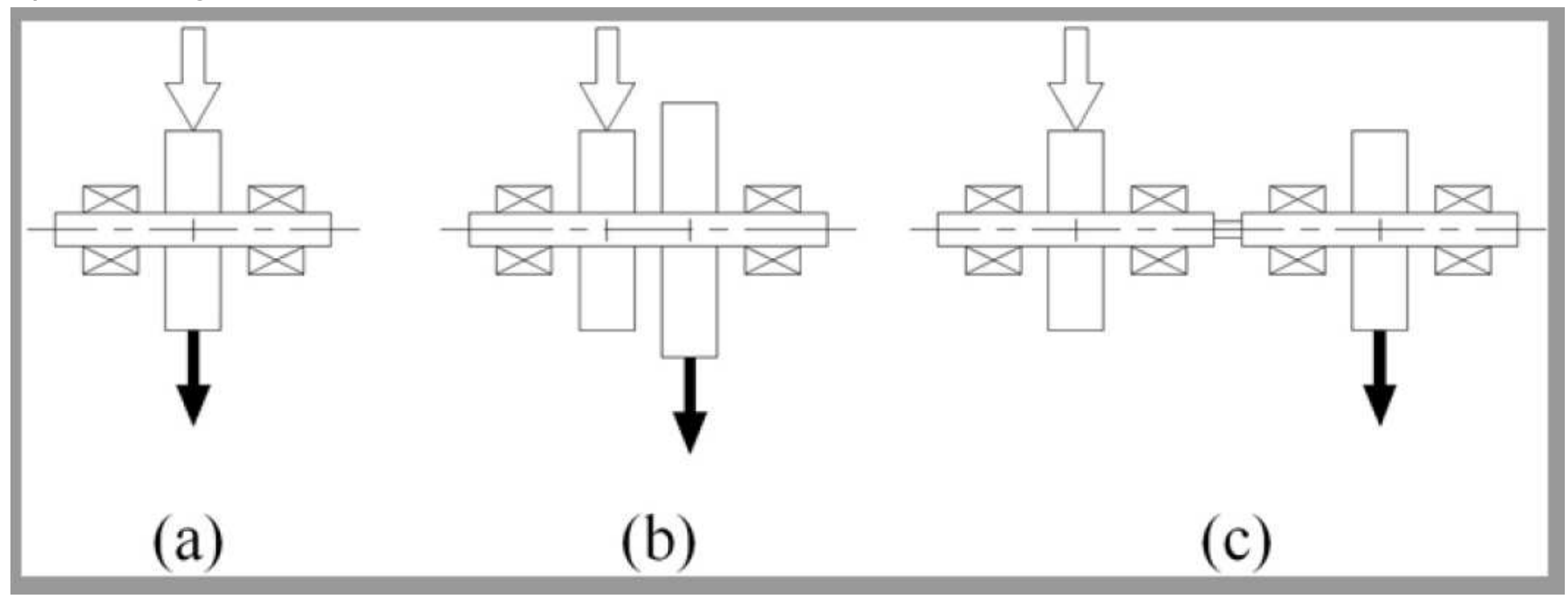

Figure 6 
Unit interface

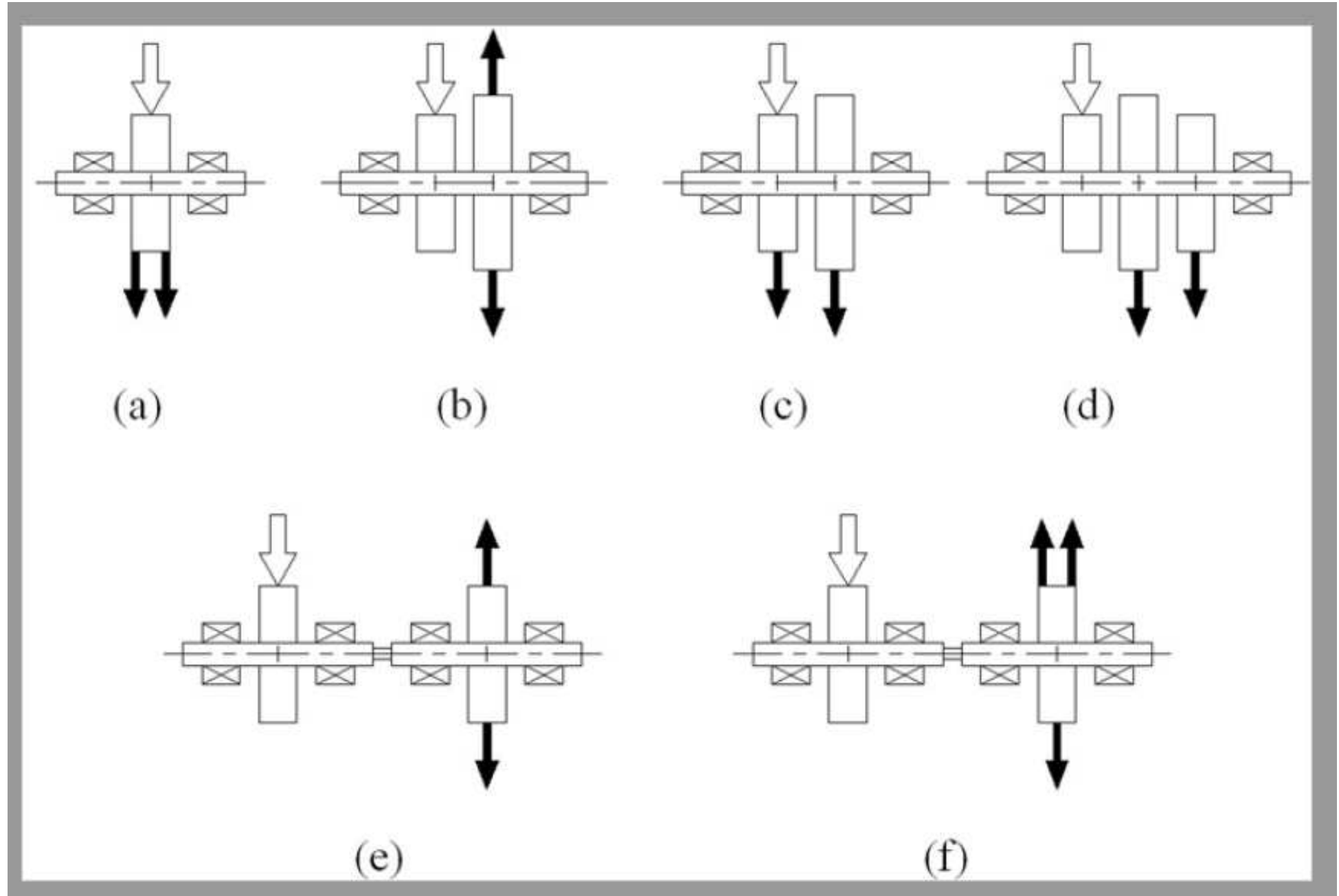

Figure 7

Subflow joint 


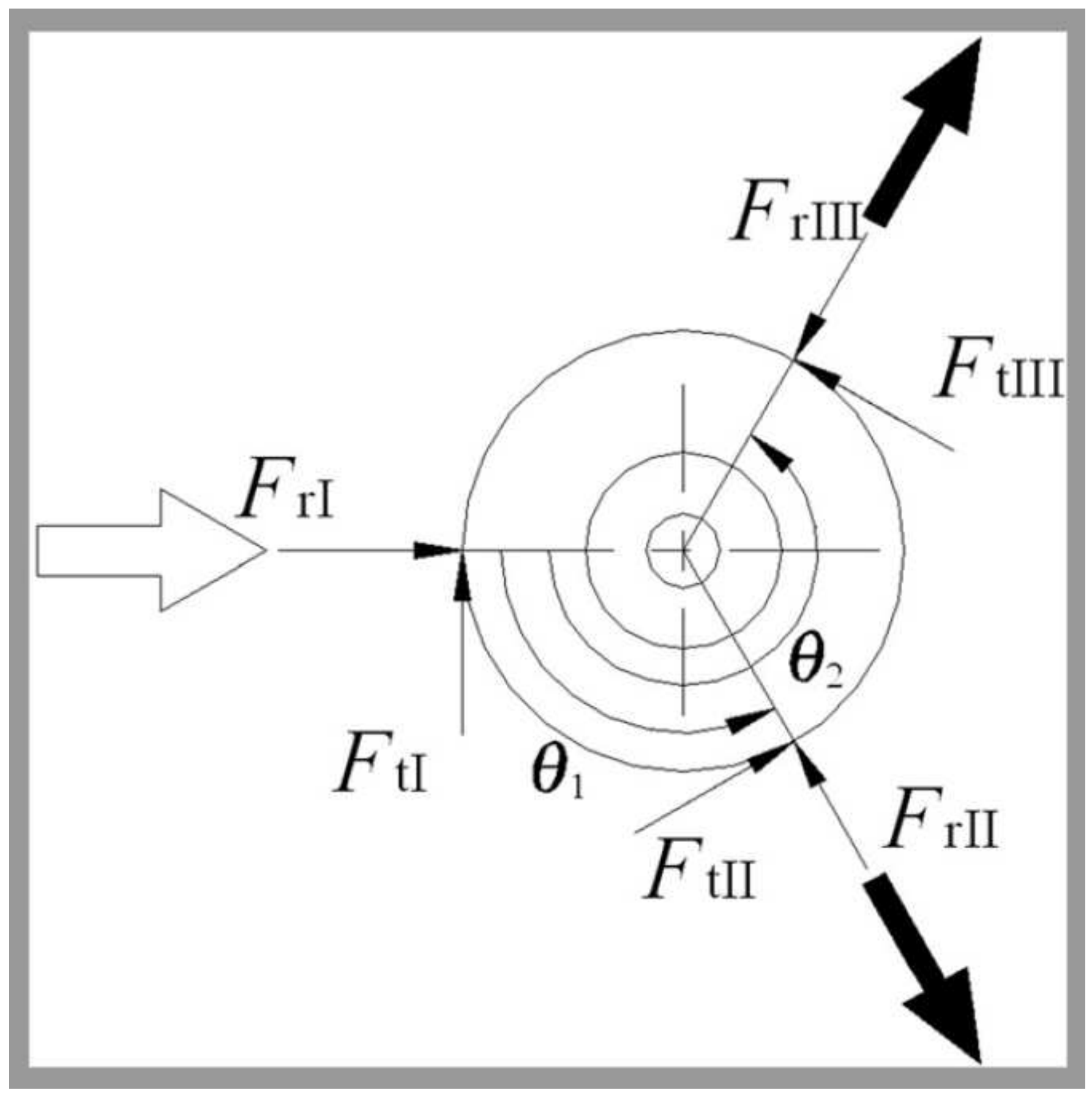

Figure 8

Gear force superposition 


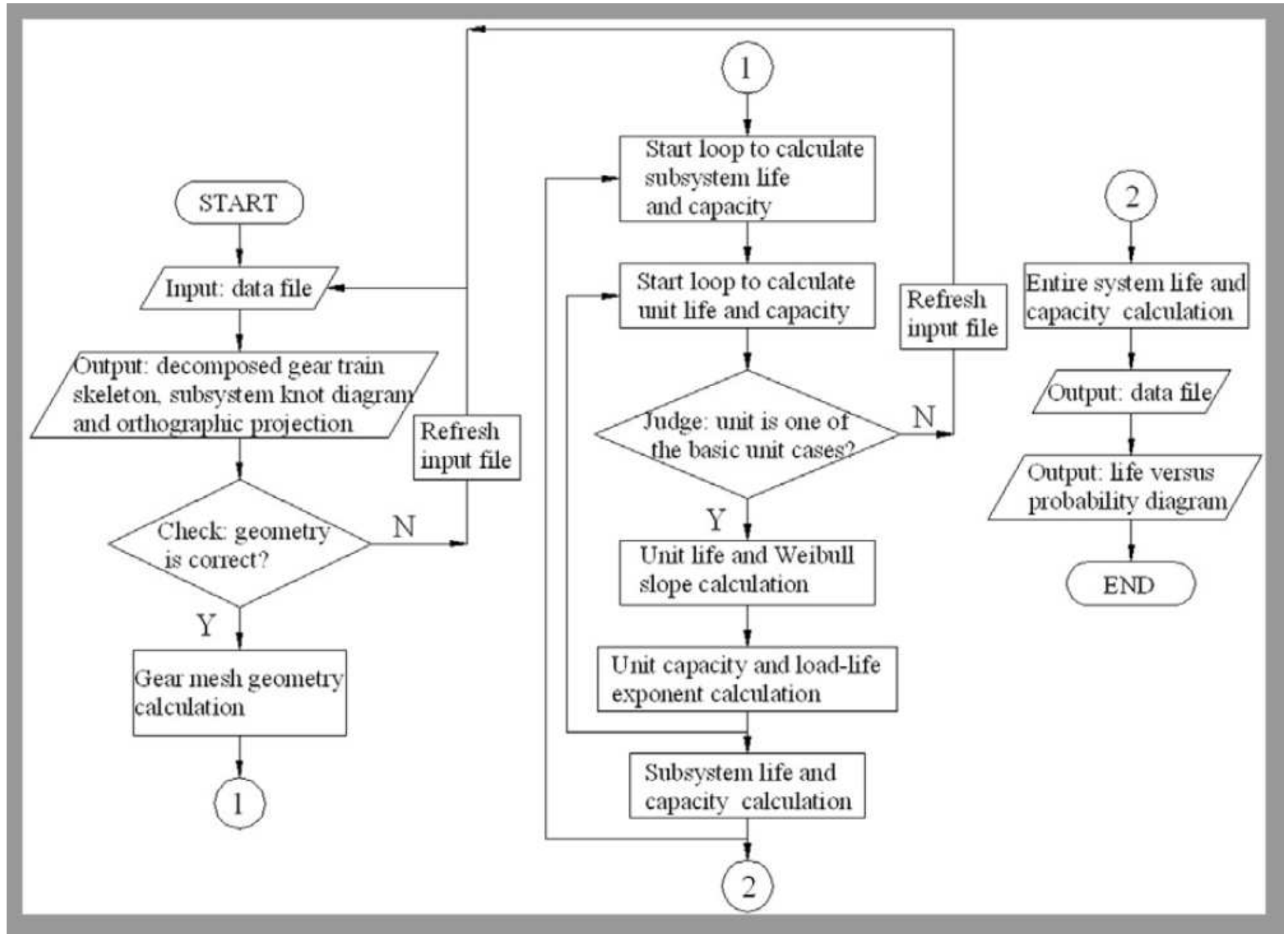

Figure 9

Program flow chart 
Save Fi gures

DECOMPOSED AGB GEAR SYSTEM SKELETON

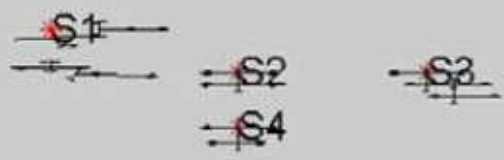

GEAR TRAIN ORTHOGRAPHIC PROJECTION
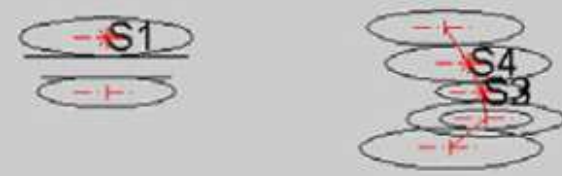

SYSTEM KNOT DIAGRAM

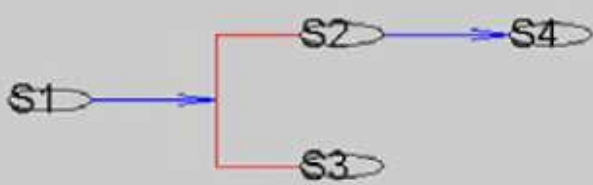

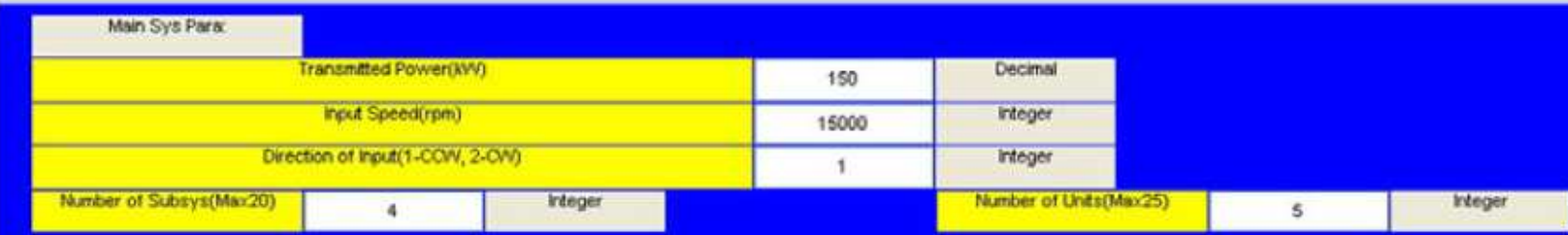

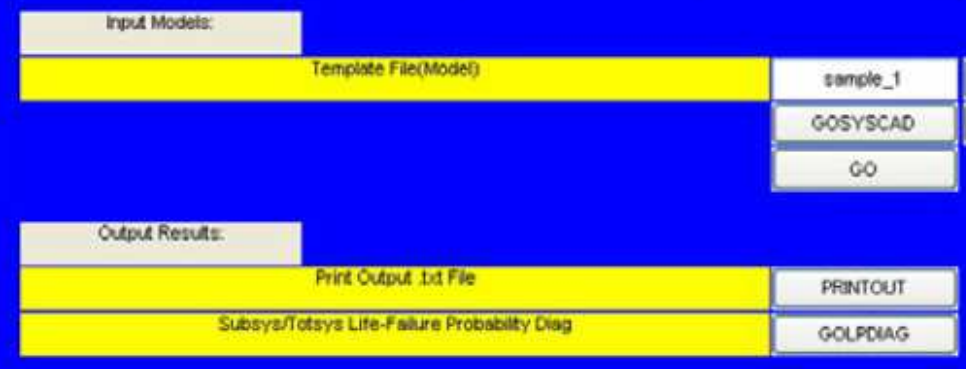

Figure 10

GUI interface of the program 


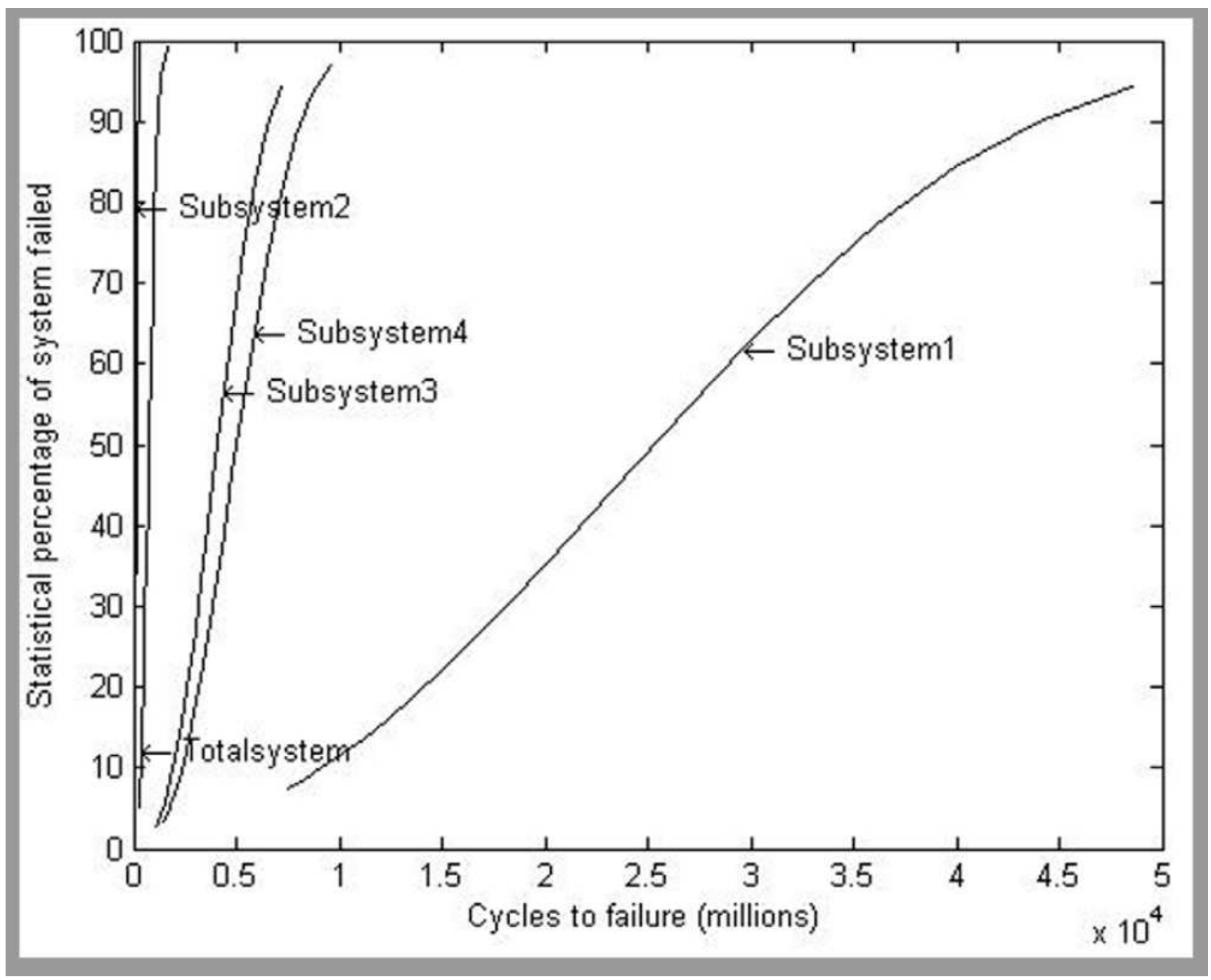

Figure 11

Life versus probability of system failure (Design 1) 


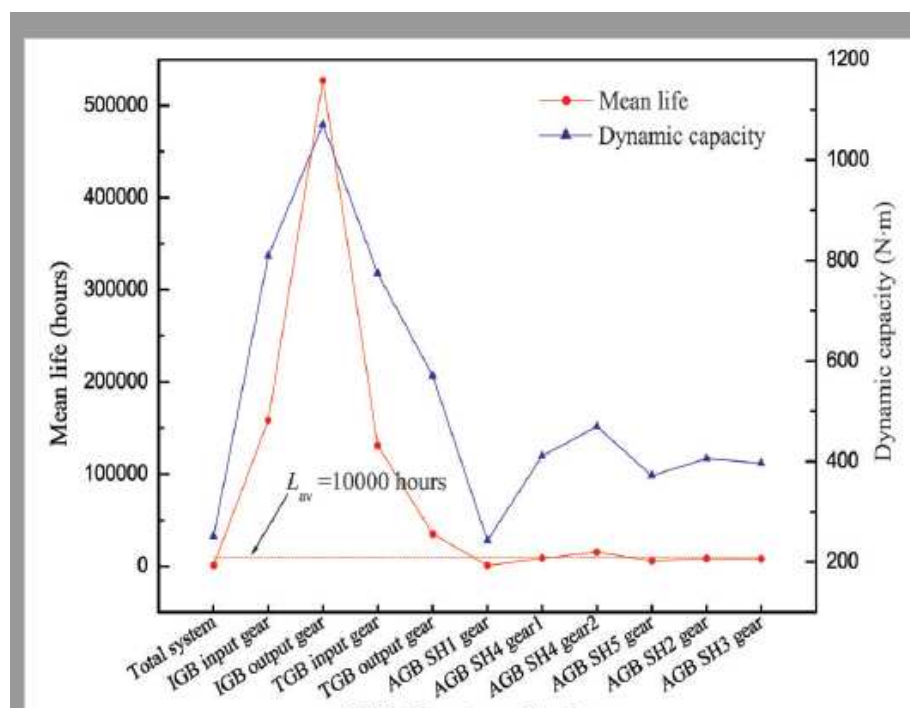

(a) Total system and each gear

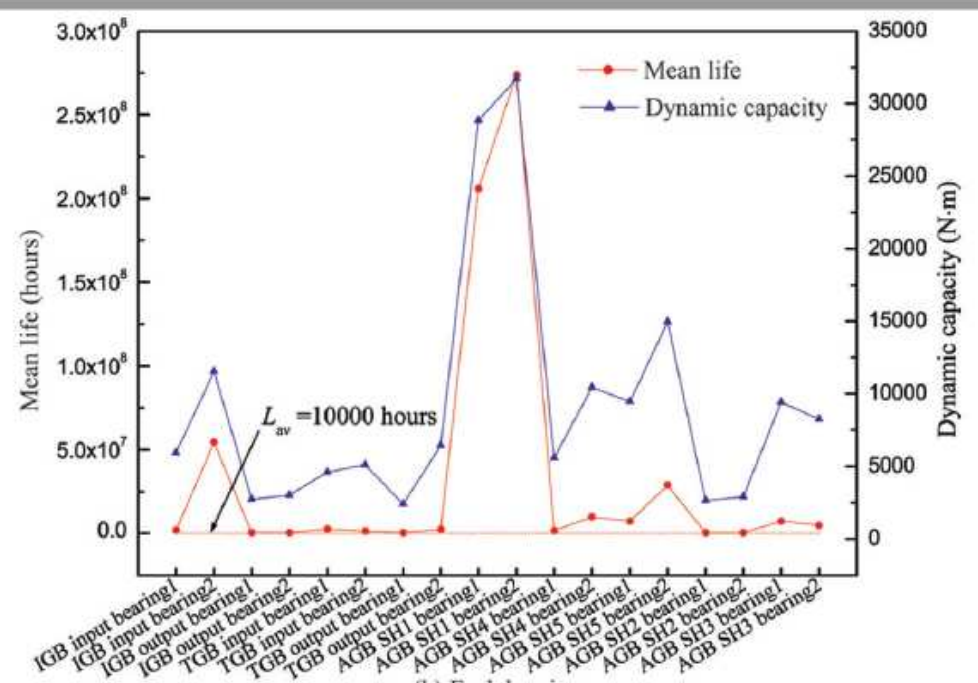

(b) Each bearing

\section{Figure 12}

Life and dynamic capacity of total system and each component (Design 1) 


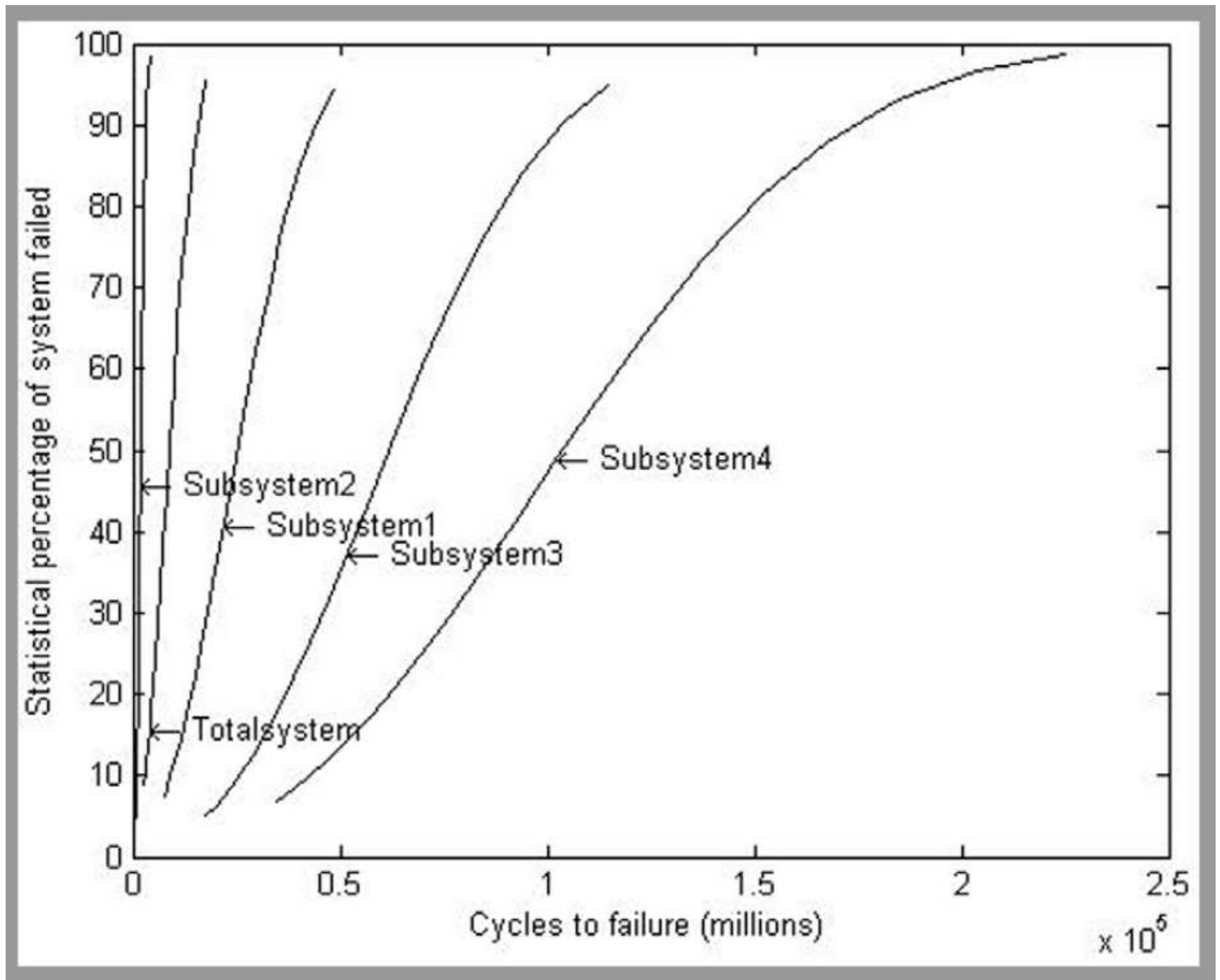

Figure 13

Life versus probability of system failure (Design2)
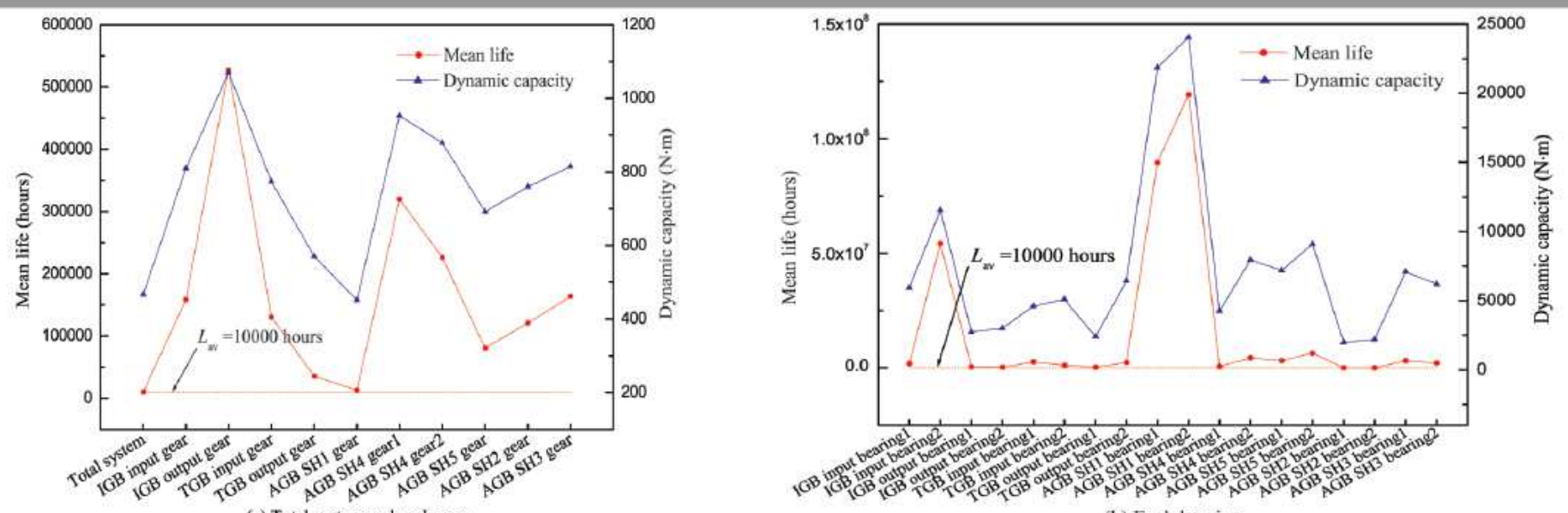
Figure 14

Life and dynamic capacity of total system and each component (Design2) 